\title{
Radioimmunoassay of primary bile salts in serum
}

\author{
Y. A. BAQIR, J. MURISON, P. E. ROSS, AND IAN A. D. BOUCHIER \\ From the Department of Medicine, Ninewells Hospital and Medical School, Dundee DD1 9SY, UK
}

SUMMARY Rapid, sensitive radioimmunoassays have been developed for the conjugated primary bile salts, cholate and chenodeoxycholate, using immunogens prepared by the mixed anhydride procedure. Antibodies produced showed equal specificity for glycine and taurine conjugates. Crossreactivities were comparable with those from other published radioimmunoassays. The assays were routinely performed on unextracted sera and the concentrations correlated well with concentrations determined by gas-liquid chromatography.

Accuracy, determined by the addition of bile salt to charcoal-extracted serum, and precision, determined by replicate analysis of a normal sample, were both less than $\pm 10 \%$. These figures are comparable with those obtained by both gas-liquid chromatography and other radioimmunoassays for bile salts.

Normal sera were found to contain 0.49-1.32 $\mu \mathrm{mol} / 1$ of cholate and 0.55-2.02 $\mu \mathrm{mol} / 1$ of chenodeoxycholate. Serum concentrations in patients with liver disease were higher than this normal range. Three patients with mild liver disturbance were found to have one bile salt in the upper limit of normal, but in each case the other primary bile salt was outwith the normal range.

Elevation of serum bile salt concentration in hepatobiliary disease (Sherlock and Walshe, 1948) has been shown to be a sensitive test for liver disease (Korman et al., 1974). Sensitive assays for individual serum bile salt conjugates may provide further useful diagnostic information (Pennington et al., 1977), but until recently only gas liquid chromatography (GLC) was capable of assaying individual bile salts in serum (van Berge Henegouwen et al., 1974; Ross et al., 1977). This methodology is technically complex and time-consuming, and consequently there is the need for a rapid assay procedure that demonstrates sensitivity, precision, and accuracy similar to gas liquid chromatography. Radioimmunoassay provides such a potential, and several methods have now been reported for bile salt conjugates (Simmonds et al., 1973; Murphy et al., 1974).

We report here the development and validation of radioimmunoassay for the conjugated primary bile salts, cholate and chenodeoxycholate, and the concentrations found in patients with hepatitis, biliary obstruction, cirrhosis, and infectious mononucleosis.

\section{Material}

\section{CHEMICALS}

Pure unlabelled bile acids were obtained from

Received for publication 12 December 1978
Maybridge Chemical Co Ltd and Steraloids Ltd. Ursodeoxycholic acid was a gift from Tokyo Tanabe Co Ltd, Japan. Glyco[ $\left.{ }^{3} \mathrm{H}\right]$ cholic acid, $1.86 \mathrm{Ci} / \mathrm{mmol}$ specific activity, and glyco $\left[{ }^{3} \mathrm{H}\right]$ chenodeoxycholic acid, $5.0 \mathrm{Ci} / \mathrm{mmol}$ specific activity, were supplied by New England Nuclear Ltd. Non-radioactive bile salts were analysed by GLC and thin-layer chromatography (TLC) and radioactive bile salts by TLC alone. No impurities exceeding $1 \%$ were found, and purification was not attempted. Scintillation liquid NE260 was obtained from Nuclear Enterprises Ltd, Freund's complete adjuvant from Difco Laboratories Ltd, bovine serum albumin from Hoechst Pharmaceuticals Ltd, and porcine $\gamma$-globulin from Koch-Light Ltd. Activated charcoal untreated powder (230-250 mesh size) was supplied by Sigma Chemical Co Ltd. All other chemicals were analytical grade.

\section{REAGENTS}

An albumin buffer was prepared which comprised $0.1 \% \mathrm{w} / \mathrm{v}$ albumin and $0.025 \% \mathrm{w} / \mathrm{v}$ porcine $\gamma$ globulin in saline buffered at $\mathrm{pH} 7.4$ by $0.01 \mathrm{M}$ phosphate.

Ammonium sulphate was prepared as a saturated solution, and the $\mathrm{pH}$ was determined to ensure that it fell within the range 4.5-5.0.

Bile salt free serum was obtained by charcoal extraction of $50 \mathrm{ml}$ serum by $2.5 \mathrm{~g}$ charcoal. After incubation at room temperature for 30 minutes the 
charcoal was removed by centrifugation at $10000 \mathrm{~g}$ for $\mathbf{2 0}$ minutes. After a further two such extractions particulate matter was removed by a Millipore filter $(0.22 \mu)$. Extraction of bile salt exceeded $99 \%$ as shown by radioactive tracer and subsequently by radioimmunoassay.

Stock bile salt standards were prepared at $0.5 \mathrm{mmol} / 1$ concentration in $0.01 \mathrm{M}$ phosphate buffer (pH 7.4). These solutions were diluted with charcoalextracted serum to give concentrations in the range 0.4-20 $\mu \mathrm{mol} / \mathrm{l}$, which were further diluted $1: 20$ with

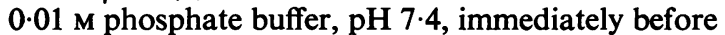
assay.

Radioactive bile salts were diluted on receipt and stored as solutions of $10 \mu \mathrm{Ci} / \mathrm{ml}$. This solution was diluted 1:300 with 0.01 M phosphate buffer ( $\mathrm{pH} 7 \cdot 4)$ before use.

\section{Methods}

\section{PREPARATION OF IMMUNOGENS}

'Mixed anhydride' conjugation

Bile salt-protein conjugation was based on the 'mixed anhydride' technique (Erlanger et al., 1957). Glycocholic acid $(0.22 \mathrm{mmol})$ was dissolved in the minimum volume of 1,4-dioxan by gentle heating, transferred to a cold room, and cooled to $8^{\circ} \mathrm{C}$, ensuring that crystallisation did not occur. Radioactive glyco $\left[{ }^{3} \mathrm{H}\right]$ cholic acid $(0 \cdot 4 \mu \mathrm{Ci})$ was added, followed by $0.22 \mathrm{mmol}$ tri- $n$-butylamine and 0.22 mmol isobutyl chloroformate. The mixture was stirred and left for 20 minutes at $4{ }^{\circ} \mathrm{C}$.

Bovine serum albumin $(4 \mu \mathrm{mol})$, dissolved in $8 \mathrm{ml}$ distilled water, was mixed with $0.5 \mathrm{ml} 0.5 \mathrm{M}$ sodium hydroxide and then $8 \mathrm{ml}$ of 1,4-dioxan. After equilibration at $4^{\circ} \mathrm{C}$ the bile acid mixture was added dropwise to the albumin solution which was stirred continuously. During this addition the $\mathrm{pH}$ was maintained in the range $8 \cdot 7-9 \cdot 2$. After addition of bile acid the reaction was allowed to proceed at $4^{\circ} \mathrm{C}$ for 1 hour when the $\mathrm{pH}$ was again checked and adjusted as necessary. The mixture was then left for a further 2 hours with constant stirring.

An aliquot of the reaction mixture $(1 \%)$ was removed to determine total radioactivity, and the remainder was dialysed overnight against $0.01 \mathrm{M}$ phosphate buffer, pH 7.4, using an Amicon micro ultrafiltration cell 8MC. Previous studies had shown that $98 \%$ of unbound bile acid could be removed by overnight dialysis.

The radioactive content of an aliquot of the dialysed fraction $(5 \%)$ was determined with the $1 \%$ aliquot of the reaction mixture and the binding was calculated.

Glycochenodeoxycholate-protein conjugates were prepared similarly.

\section{IMMUNISATION}

Immunogens were diluted to protein concentrations of $1 \mathrm{mg} / \mathrm{ml}$ and emulsified with an equal volume of Freund's complete adjuvant by an interlocking syringe technique until a stiff water in oil emulsion had been obtained (Berlin and McKinney, 1958).

These emulsions were injected into 10 intradermal sites $(0.2 \mathrm{ml} / \mathrm{site})$ along both flanks on each rabbit, and blood was taken at 6,9 , and 12 weeks after immunisation and 10 days after each booster injection. Intramuscular booster injections $(1 \mathrm{ml}$ into each thigh) were given when the antibody titre remained unchanged or fell.

\section{COLLECTION OF SAMPLES FOR ANALYSIS}

Specimens of venous blood $(10 \mathrm{ml})$ were obtained at 0900 hours after a 12-hour fast. Blood was allowed to clot at room temperature, and the serum was separated by centrifugation and immediately deep frozen until assayed.

\section{RADIOIMMUNOASSAY PROCEDURE}

Antiserum was diluted with albumin buffer such that the final dilution used in the radioimmunoassay gave $55 \%$ antibody bound. Normal sera were diluted

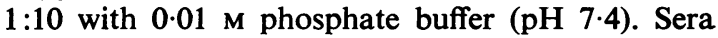
from patients with liver disease were initially diluted $1: 50$, and this dilution was altered if necessary to bring the concentration within the range of the standard curve.

Standard or serum $(0 \cdot 1 \mathrm{ml})$, glyco $\left[{ }^{3} \mathrm{H}\right]$ cholic acid tracer $(0.3 \mathrm{ml})$, and antiserum $(0.2 \mathrm{ml})$ were added to a $3 \mathrm{ml}$ test-tube, mixed, and incubated at room temperature for 1 hour. Saturated ammonium sulphate $(0.6 \mathrm{ml})$ was added to the tubes, thoroughly mixed, and equilibrated to $4^{\circ} \mathrm{C}$ for 45 minutes before centrifugation at $4^{\circ} \mathrm{C}$ for 30 minutes at $1500 \mathrm{~g}$. An aliquot of supernatant $(0.5 \mathrm{ml})$ was mixed with $8 \mathrm{ml}$ NE260 liquid scintillator, and the radioactivity was determined. Quenching was constant, and therefore counts per minute were not converted to disintegrations per minute.

The procedure for radioimmunoassay of chenodeoxycholate conjugates was identical with the above, with the substitution of the appropriate tracer and antiserum.

Some sera were assayed after extraction by the same method as that reported by Ross et al. (1977), although the volume of serum used was $0.1 \mathrm{ml}$ and the volume of ethanol was reduced proportionately.

\section{Results}

\section{ANTISERA SPECIFICITY}

The cross-reactivities of antisera to other bile salts, 
Table 1 Antisera cross-reactivities

\begin{tabular}{lc}
\hline & $\begin{array}{l}\text { Percentage } \\
\text { cross-reaction }\end{array}$ \\
\hline Cholate antisera & 100 \\
Taurocholate & 19.4 \\
Cholic acid & 11.7 \\
Glycochenodeoxycholate & 5.0 \\
Glycodeoxycholate & 1.3 \\
Glycolithocholate & 1 \\
Glycoursodeoxycholate & 100 \\
Chenodeoxycholate antisera & 10 \\
Taurochenodeoxycholate & 1.0 \\
Chenodeoxycholic acid & 1.3 \\
Glycocholate & 1.0 \\
Glycolithocholate & $<$ \\
Glycoursodeoxycholate & 1 \\
Glycodeoxycholate & $<$ \\
Ursodeoxycholate & 1 \\
\hline
\end{tabular}

determined by the method of Abraham (1969), are shown in Table 1.

Cholate standards in the range 5-100 pmol and chenodeoxycholate standards in the range $2-50 \mathrm{pmol}$ were converted into logit form to obtain linear relationships (Fig. 1).

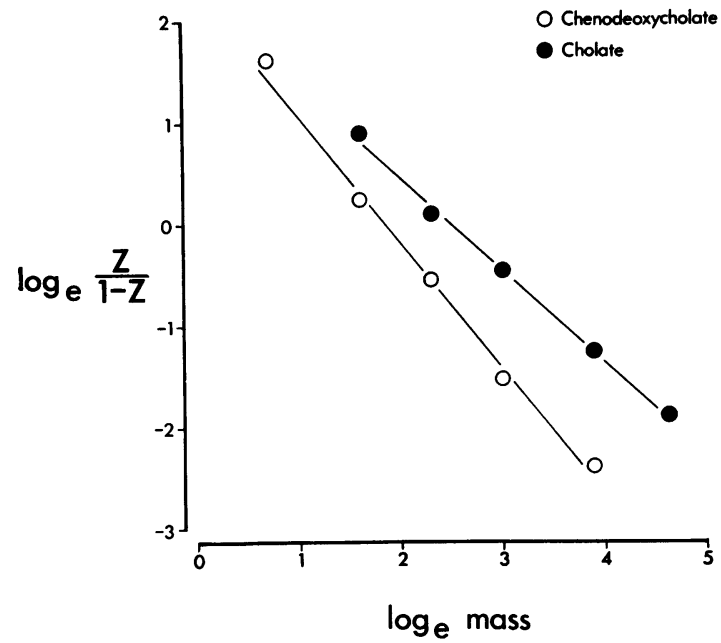

Fig. 1 Logit plot of bile salt standards

where $z=\frac{\text { bound/free ratio }}{\text { bound/free ratio at zero mass of standard }}$.

SERUM EXTRACTIONS

The results (Table 2) of five random serum samples estimated with and without extraction showed no significant difference by Student's $t$ test for paired observations or Wilcoxon Rank test at the $95 \%$ confidence level.

ACCURACY AND PRECISION

The accuracy of the estimation was assessed by comparison with values for 20 serum samples ob-
Table 2 Radioimmunoassay of extracted and unextracted samples

\begin{tabular}{|c|c|c|}
\hline & $\begin{array}{l}\text { Cholate } \\
(\mu \mathrm{mol} / \mathrm{l})\end{array}$ & $\begin{array}{l}\text { Chenodeoxycholate } \\
\text { ( } \mu \mathrm{mol} / \mathrm{I})\end{array}$ \\
\hline \multicolumn{3}{|l|}{ Unextracted samples } \\
\hline$(\mathrm{n}=5) \quad \begin{array}{l}\text { Range } \\
\text { Mean }\end{array}$ & $\begin{array}{l}2 \cdot 28-17.8 \\
6.90\end{array}$ & $\begin{array}{l}7 \cdot 30-19 \cdot 4 \\
12 \cdot 9\end{array}$ \\
\hline \multicolumn{3}{|l|}{ Extracted samples } \\
\hline $\begin{array}{ll}(n=5) & \begin{array}{l}\text { Range } \\
\text { Mean }\end{array}\end{array}$ & $\begin{array}{l}2 \cdot 37-18 \cdot 3 \\
6 \cdot 70\end{array}$ & $\begin{array}{l}6 \cdot 27-20.9 \\
12 \cdot 8\end{array}$ \\
\hline $\begin{array}{l}\text { Standard deviation of } \\
\text { difference in paired } \\
\text { values }\end{array}$ & 0.481 & 1.628 \\
\hline
\end{tabular}

tained by a gas liquid chromatographic method (Ross et al., 1977) (Fig. 2). The samples were obtained from control subjects and patients with mild liver disorders diagnosed as described by Pennington $e t$ al. (1977).

Ten assays of the same sample were performed in a similar manner, and the mean, standard deviation, and coefficient of variation were calculated. Replicate analyses gave a mean serum cholate concentration of $0.96 \pm 0.11 \mu \mathrm{mol} / 1$ (coefficient of variation $11.8 \%$ ), while the mean serum chenodeoxycholate concentration was $1.80 \pm 0.15 \mu \mathrm{mol} / 1$ (coefficient of variation $8.6 \%$ ). Precision and accuracy determined on samples containing high levels of bile salts indicated similar coefficients of variation to those determined on normal sera.

\section{SERUM CONCENTRATIONS}

Values obtained from the fasting serum samples of 10 normal healthy volunteers, aged $25-45$ years with no gastrointestinal complaints, gave a mean cholate concentration of $0.96 \mu \mathrm{mol} / \mathrm{l}$ and a mean chenodeoxycholate concentration of $1.26 \mu \mathrm{mol} / 1$. Compared with normal subjects patients with cirrhosis showed a mean cholate concentration of $15.2 \mu \mathrm{mol} / \mathrm{l}$, and for chenodeoxycholate the concentration was $29.0 \mu \mathrm{mol} / 1$. These levels were exceeded in patients with obstruction, where the mean concentrations were $56.7 \mu \mathrm{mol} / 1$ and $38.1 \mu \mathrm{mol} / 1$, respectively, and in patients with hepatitis with mean concentrations of 50.7 and $42.4 \mu \mathrm{mol} / 1$, respectively. Patients with infectious mononucleosis showed only slightly elevated levels, the mean cholate concentration being $4.0 \mu \mathrm{mol} / 1$ and the mean chenodeoxycholate concentration $8.59 \mu \mathrm{mol} / 1$. These mean concentrations, together with the range of levels, are reported in Table 3. Standard deviations are not reported as the distribution of concentrations is skewed.

\section{Discussion}

Reports so far have been divided between the use of 'carbodiimide' (Simmonds et al., 1973; Demers and 


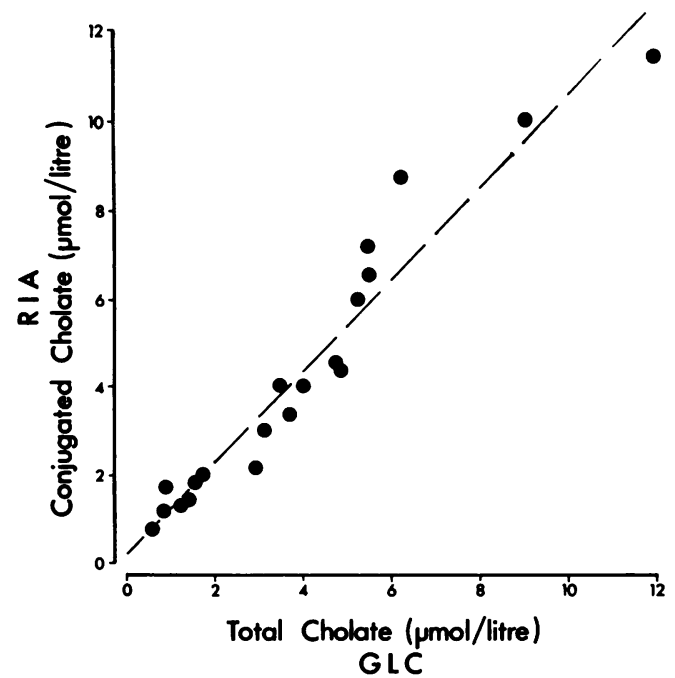

a)

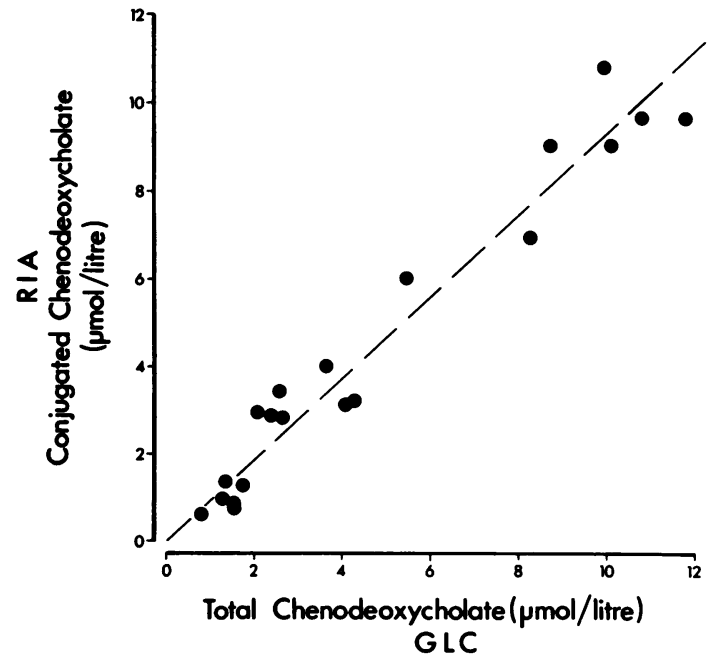

b)

Fig. 2 (a) Relationship between conjugated cholate values (RIA) and total cholate values $(G L C): n=20$; correlation coefficient $r=0.968$. (b) Relationship between conjugated chenodeoxycholate values $(R I A)$ and total chenodeoxycholate values $(G L C): n=20$; correlation coefficient $r=0.976$.

Hepner, 1976) and 'mixed anhydride' procedures (Murphy et al., 1974; Matern et al., 1976) for the preparation of bile salt immunogens. In our experience, the carbodiimide procedure gave consistently poorer conjugation than mixed anhydride, a
Table 3 Serum concentrations and ranges of primary bile salts in normals and patients with liver disease

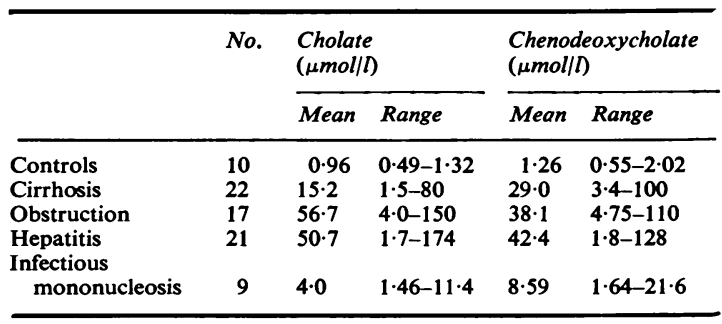

fact predicted on theoretical grounds. The carbodiimide reaction is favoured by an acid $\mathrm{pH}$ but must be carried out near to $\mathrm{pH} 8$ as protein amino groups are not reactive at lower $\mathrm{pH}$ values, and bile salts would precipitate below pH 4-7-4:3. While low molar ratios for bile salt bound to albumin do not necessarily preclude the production of antisera, in our experience, conjugates with bile salt:albumin ratios of less than 10:1 did not produce an antiserum which could be used for radioimmunoassay.

Antisera showed equal affinity for glycine and taurine conjugates but the affinity for unconjugated bile salts was $<12 \%$ of that for conjugates (Table 1 ). Bile salts in peripheral blood are predominantly conjugated as indicated by the correlation of gas chromatography results (total levels) with radioimmunoassay results (conjugates) (Fig. 2). Total bile salts will be measured low by radioimmunoassay if high levels of unconjugated bile salts are present in serum, and these must therefore be taken into account in clinical situations where they are known to be found (Makino et al., 1969).

Although most antisera recently produced for bile salt radioimmunoassay have shown equal affinity for glycine and taurine conjugates, antisera specific to glycine conjugates have been reported (Demers and Hepner, 1976), while Mihas et al. (1977) have reported variations in specificity between taurine and glycine conjugates, depending on the antiserum dilution. Apart from the cross-reactivities of chenodeoxycholate conjugates to cholate antiserum, interference from other bile salts was within acceptable limits (Table 1).

Murphy et al. (1974) and Matern et al. (1976) reported that serum must be extracted before analysis, but the present study showed no difference between the assay of extracted and unextracted serum, and consequently serum was assayed unextracted (Table 2).

The coefficient of variation after analysis of replicate samples and correlation of data by this method and gas liquid chromatography show that radioimmunoassay is reliable, while analysis of 
charcoal-extracted serum containing added bile salt indicates acceptable accuracy. As detection limits are also lower than those reported for GLC analysis, this suggests that radioimmunoassay is suitable for routine serum bile salt analysis.

Chenodeoxycholate concentrations in normal sera are similar to those reported by GLC (van Berge Henegouwen et al., 1974; Laatikainen and Hesso, 1975; Ross et al., 1977) but are lower than those reported by Schalm et al. (1977) using a similar radioimmunoassay procedure. However, these authors expressed concern at over-estimation by their procedure when compared with a GLC procedure. Cholate concentrations in normal sera also showed good agreement with reported concentrations determined by GLC (Makino et al., 1969; Laatikainen and Hesso, 1975; Ross et al., 1977) but were lower than the range reported by van Berge Henegouwen et al. (1974). The radioimmunoassays of Simmonds et al. (1973) and Matern et al. (1976) gave similar ranges for normal subjects.

Primary serum bile salt concentrations were elevated in all four groups studied compared with the normal range. In each group, excepting those patients with obstruction, a few patients had concentrations of one bile salt which was within the normal range, but in each case the other primary bile salt concentration was elevated.

Radioimmunoassay, therefore, provides a rapid method for the study of primary serum bile acids in normal subjects and patients with liver disease.

We thank Dr H. M. Fraser, MRC Unit for Reproductive Biology, Edinburgh for assistance in the production of antibodies in rabbits and Mrs $\mathrm{C}$. Hall for technical assistance. We also acknowledge support from Mason Medical Research Foundation.

\section{References}

Abraham, G. E. (1969). Solid-phase radioimmunoassay of estradiol-17 $\beta$. Journal of Clinical Endocrinology and Metabolism, 29, 866-870.

Berlin, B. S., and McKinney, R. W. (1958). A simple device for making emulsified vaccines. Journal of Laboratory and Clinical Medicine, 52, 657-658.

Erlanger, B. F., Borek, F., Beiser, S. M., and Lieberman, S. (1957). Steroid-protein conjugates. I. Preparation and characterization of conjugates of bovine serum albumin with testosterone and with cortisone. Journal of Biological Chemistry, 228, 713-727.
Demers, L. M., and Hepner, G. (1976). Radioimmunoassay of bile acids in serum. Clinical Chemistry, 22, 602-606.

Korman, M. G., Hofmann, A. F., and Summerskill, W. J. H. (1974). Assessment of activity in chronic active liver disease. Serum bile acids compared with conventional tests and histology. New England Journal of Medicine, 290, 1399-1402.

Laatikainen, T., and Hesso, A. (1975). Determination of serum bile acids by glass capillary gas-liquid chromatography. Clinica Chimica Acta, 64, 63-68.

Makino, I., Nakagawa, S., and Mashimo, K. (1969). Conjugated and unconjugated serum bile acid levels in patients with hepatobiliary diseases. Gastroenterology, 56, 1033-1039.

Matern, S., Krieger, R., and Gerok, W. (1976). Radioimmunoassay of serum conjugated cholic acid. Clinica Chimica Acta, 72, 39-48.

Mihas, A. A., Spenney, J. G., Hirschowitz, B. I., and Gibson, R. G. (1977). A critical evaluation of a procedure for measurement of serum bile acids by radioimmunoassay. Clinica Chimica Acta, 76, 389-397.

Murphy, G. M., Edkins, S. M., Williams, J. W., and Catty, D. (1974). The preparation and properties of an antiserum for the radioimmunoassay of serum conjugated cholic acid. Clinica Chimica Acta, 54, 81-89.

Pennington, C. R., Ross, P. E., and Bouchier, I. A. D. (1977). Serum bile acids in the diagnosis of hepatobiliary disease. Gut, 18, 903-908.

Pennington, C. R., Ross, P. E., and Bouchier, I. A. D. (1978). Serum bile acids in patients with viral hepatitis. Scandinavian Journal of Gastroenterology, 13, 77-80.

Ross, P. E., Pennington, C. R., and Bouchier, I. A. D. (1977). Gas-liquid chromatographic assay of serum bile acids. Analytical Biochemistry, 80, 458-465.

Schalm, S. W., van Berge Henegouwen, G. P., Hofmann, A. F., Cowen, A. E., and Turcotte, J. (1977). Radioimmunoassay of bile acids: development, validation, and preliminary application of an assay for conjugates of chenodeoxycholic acid. Gastroenterology, 73, 285-290.

Sherlock, S., and Walshe, V. (1948). Blood cholates in normal subjects and in liver disease. Clinical Science, 6, 223-234.

Simmonds, W. J., Korman, M. G., Go, V. L. W., and Hofmann, A. F. (1973). Radioimmunoassay of conjugated cholyl bile acids in serum. Gastroenterology, 65, 705-711.

van Berge Henegouwen, G. P., Ruben, A., and Brandt, K. H. (1974). Quantitative analysis of bile acids in serum and bile, using gas-liquid chromatography. Clinica Chimica Acta, 54, 249-261.

Requests for reprints to: J. Murison, Department of Medicine, Ninewells Hospital and Medical School, Dundee DD1 9SY, UK. 